\title{
Comparison of Packing Modes of Poly(thiophene)s and Poly(thiazole)s
}

\author{
Takakazu Yamamoto, ${ }^{\dagger}$ Bang-Lin Lee, Hajime Suganuma, \\ and Shintaro SASAKI* \\ Research Laboratory of Resources Utilization, Tokyo Institute of Technology, \\ 4259 Nagatsuta, Midori-ku, Yokohama 226-8503, Japan \\ * Japan Advanced Institute of Science and Technology, I-1 Asahidai. \\ Tatsunokuchi, Ishikawa 923-1292, Japan
}

(Received February 16, 1998)

\begin{abstract}
KEY WORDS Packing Mode / X-Ray Crystallography / Head-to-Tail Type Poly(3-methylthiophene2,5-diyl) / Head-to-Head Type Poly(thiazole-2,5-diyl) /
\end{abstract}

$\pi$-Conjugated polymers constituted of recurring fivemembered hetero-aryl rings, e.g.,

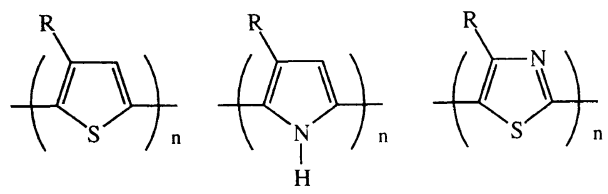

polythiophene $^{1-3}$ polypyrrole polythiazole $^{5}$ $\mathrm{R}=\mathrm{H}, \mathrm{CH}_{3}, n-\mathrm{C}_{6} \mathrm{H}_{13}$, etc.

have been the subject of recent many papers. These polymers show interesting electronic and optical properties including electrically conducting properties, light emitting properties, and relatively large third-order nonlinear optical susceptibility $\chi^{(3)}$. They have already found practical usage (e.g., electrodes for capacitors ${ }^{6}$ and conducting films to remove static electricity).

Among these polymers, those with $\mathrm{R}=\mathrm{H}$ and $\mathrm{CH}_{3}$ are particularly interesting since they can form a linear coplanar molecular structure due to minor steric repul-
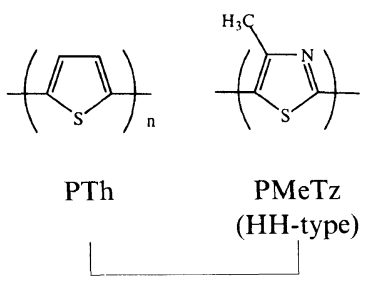

reported $^{5,7}$

sion brought by $\mathrm{H}$ and $\mathrm{CH}_{3},{ }^{3,5}$ in contrast to other polymers having longer alkyl chains like a hexyl group.

Of the five-membered ring polymers with $\mathrm{R}=\mathrm{H}$ and $\mathrm{R}=\mathrm{CH}_{3}$, packing structures of poly(thiophene-2,5diyl) ${ }^{7}$ and head-to-head HH type poly(4-methylthiazole2,5 -diyl) ${ }^{5}$ in the solid state have been reported. However, comparison of packing structures of poly(thiophene-2,5diyl) and poly(3-methylthiophene-2,5-diyl) with the corresponding poly(thiazole-2,5-diyl) and poly(4-methylthiazole-2,5-diyl) has not been reported. For better un-<smiles>Cc1cc(C)c(Br)s1</smiles>

$\left(\mathrm{Me}_{3} \mathrm{Sn}-\mathrm{MeTh}-\mathrm{Br}\right)$

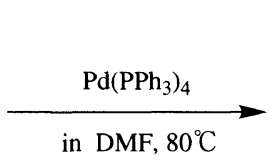

in $\mathrm{DMF}, 80^{\circ} \mathrm{C}$

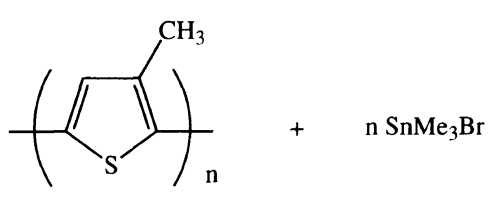

HT-P3MeTh<smiles>CCCCCCCCCSc1cnc(-c2ncc(SC)s2)s1</smiles>

$\left(\mathrm{Me}_{3} \mathrm{Sn}-\mathrm{Tz}-\mathrm{Tz}-\mathrm{SnMe}_{3}\right)$

(Br-Tz-Tz-Br)

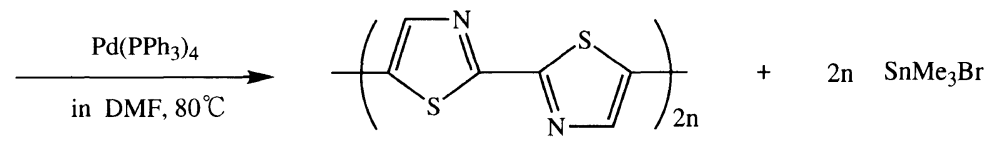

HH-PTz

$\mathrm{Me}_{3} \mathrm{Sn}=$ trimethylstannyl group

$\mathrm{Pd}\left(\mathrm{PPh}_{3}\right)_{4}=$ tetrakis(triphenylphosphine)palladium $(0)$

\footnotetext{
$\dagger^{\dagger}$ To whom correspondence should be addressed.
} 
derstanding of the five-membered ring polymers, we have prepared regioregular head-to-tail HT type P3MeTh, HT-P3MeTh, and HH type PTz, HH-PTz, by using a Stille reaction (eq 1 and 2 ), ${ }^{8}$ which has given $\pi$-conjugated polymers with well-characterized bondings between the monomeric units, ${ }^{5,9-11}$ and herein report packing modes of HT-P3MeTh and HH-PTz.

\section{EXPERIMENTAL}

HT-P3MeTh (eq 1) was prepared from 2-bromo-5trimethylstannyl-3-methylthiophene, $\mathrm{Me}_{3} \mathrm{Sn}-\mathrm{MeTh}-\mathrm{Br}$, by using the Stille reaction developed by McCullough and his coworkers. ${ }^{11}$ 2-Bromo-3-methylthiophene was prepared according to the literature, ${ }^{12}$ and this compound was treated with lithium diisopropylamide at $-70^{\circ} \mathrm{C}$. To the reaction mixture was added $\mathrm{Me}_{3} \mathrm{SnCl}$, and stirring at $-50^{\circ} \mathrm{C}$ for $1 \mathrm{~h}$ followed by distillation $\left(66-67^{\circ} \mathrm{C} /\right.$ 1.5-1.7 mmHg) gave colorless $\mathrm{Me}_{3} \mathrm{Sn}-\mathrm{MeTh}-\mathrm{Br}$ in $69 \%$ yield. Anal. Found: C, 28.3; H, 3.7\%. Calcd for: C, 28.3; $\mathrm{H}, 3.9 \% .{ }^{1} \mathrm{H}$ NMR $\left(400 \mathrm{MHz}, \mathrm{CDCl}_{3}\right): \delta 0.35$ flanked by two satelite peaks due to couplings with ${ }^{117} \mathrm{Sn}$ and ${ }^{119} \mathrm{Sn}(J=29 \mathrm{~Hz})(9 \mathrm{H}), 2.13(3 \mathrm{H}), 6.95(1 \mathrm{H})$. Polymerization was carried out in dry $N, N$-dimethylformamide (DMF) at $80^{\circ} \mathrm{C}$ by using tetrakis(triphenylphosphine)palladium $(0),{ }^{13} \mathrm{Pd}\left(\mathrm{PPh}_{3}\right)_{4}$, as the catalyst $(2 \mathrm{~mol} \%$ per $\mathrm{Me}_{3} \mathrm{Sn}-\mathrm{MeTh}-\mathrm{Br}$ ).

HH-PTz was prepared analogously by using 5,5'-bis(trimethylstannyl)-2,2'-bithiazole $\left(\mathrm{Me}_{3} \mathrm{Sn}-\mathrm{Tz}-\mathrm{Tz}-\mathrm{SnMe} \mathrm{Me}_{3}\right)$ and 5,5'-dibromo-2,2'-bithiazole (Br-Tz-Tz-Br) (eq 2). $\mathrm{Me}_{3} \mathrm{Sn}-\mathrm{Tz}-\mathrm{Tz}-\mathrm{SnMe}_{3}$ was prepared according to the literature. ${ }^{14} \mathrm{Br}-\mathrm{Tz}-\mathrm{Tz}-\mathrm{Br}$ was prepared by bromination of $2,2^{\prime}$-bithiazole ${ }^{15}$ with bromine at room temperature in chloroform, followed by column chromatography. $\mathrm{Br}-\mathrm{Tz}-\mathrm{Tz}-\mathrm{Br}$ was obtained as a white powder in $28 \%$ yield. Anal. Found: C, 22.4; H, 0.4; N, 8.7\%. Calcd for: C, 22.1 ; H. 0.6; N, 8.6\%. IR (KBr, $\left.\mathrm{cm}^{-1}\right): 1462,1375$, 998, 918. ${ }^{1} \mathrm{H} \mathrm{NMR}\left(400 \mathrm{MHz}, \mathrm{CDCl}_{3}\right): \delta 7.76 .{ }^{13} \mathrm{C} \mathrm{NMR}$ $\left(100 \mathrm{MHz}, \mathrm{CDCl}_{3}\right): \delta 111.5\left(5,5^{\prime}-\mathrm{C}\right), 145.2\left(4,4^{\prime}-\mathrm{C}\right), 162.0$
$\left(2,2^{\prime}-\mathrm{C}\right)$.

HT-P3MeTh and HH-PTz thus obtained were worked up in a manner similar to that previously reported. ${ }^{5,9}$ They were only partly soluble in $\mathrm{CHCl}_{3}$ and $\mathrm{CF}_{3} \mathrm{COOH}$, respectively. Powder $\mathrm{X}$-ray diffraction patterns were obtained by using a Philips PW1000 X-ray diffractometer. Density of polymer was determined by sink and float test.

\section{RESULTS AND DISCUSSION}

The polycondensation expressed by eq 1 and 2 gives HT-P3MeTh and HH-PTz quantitatively. The IR spectrum of HT-P3MeTh (Figure 1) is almost identical to that of previously reported random $\mathrm{P} 3 \mathrm{MeTh},{ }^{3,16}$ rand$\mathrm{P} 3 \mathrm{MeTh}$, and absorption bands of the monomer $\left(\mathrm{Me}_{3} \mathrm{Sn}-\mathrm{MeTh}-\mathrm{Br}\right)$ due to $v(\mathrm{C}-\mathrm{Br})\left(984 \mathrm{~cm}^{-1}\right)$ and $v\left(\mathrm{Sn}-\mathrm{CH}_{3}\right)\left(770\right.$ and $\left.728 \mathrm{~cm}^{-1}\right)$ are not observable, indicating that the polycondensation expressed by eq 1 proceeds well. The IR spectrum of HT-P3MeTh, however, exhibits a difference from that of random $\mathrm{P} 3 \mathrm{MeTh}$, concerning the absorptions at about $1450 \mathrm{~cm}^{-1}$ which are assigned to ring vibrations of the thiophene unit. Regular HT-P3MeTh gives rise to two sharp absorption peaks at 1453 and $1436 \mathrm{~cm}^{-1}$, whereas the former peak is much weakened in the IR spectrum of random $\mathrm{P} 3 \mathrm{MeTh}$. On these bases, the former peak is related to a crystalline part of $\mathrm{P} 3 \mathrm{MeTh}$ formed with a regio-regular (HT-regular) part of $\mathrm{P} 3 \mathrm{MeTh}$. The reflection spectrum of solid HT-P3MeTh (color = brown) and Kramers-Kronig transformation indicate the existence of an absorption peak at $420 \mathrm{~nm}$, which is shifted by about $20000 \mathrm{~cm}^{-1}$ from that of methylthiophene $\left(\lambda_{\max }=\right.$ $230 \mathrm{~nm})$ due to the expansion of the $\pi$-conjugation system. A part of HT-P3MeTh is soluble in $\mathrm{CHCl}_{3}$ and the $\mathrm{CHCl}_{3}$ solution shows an absorption peak at $432 \mathrm{~nm}$. The color (brown) of HH-PTz as well as its $\pi-\pi^{*}$ absorption band at $434 \mathrm{~nm}$ in trifluoroacetic acid also indicates expansion of the $\pi$-conjugation system from

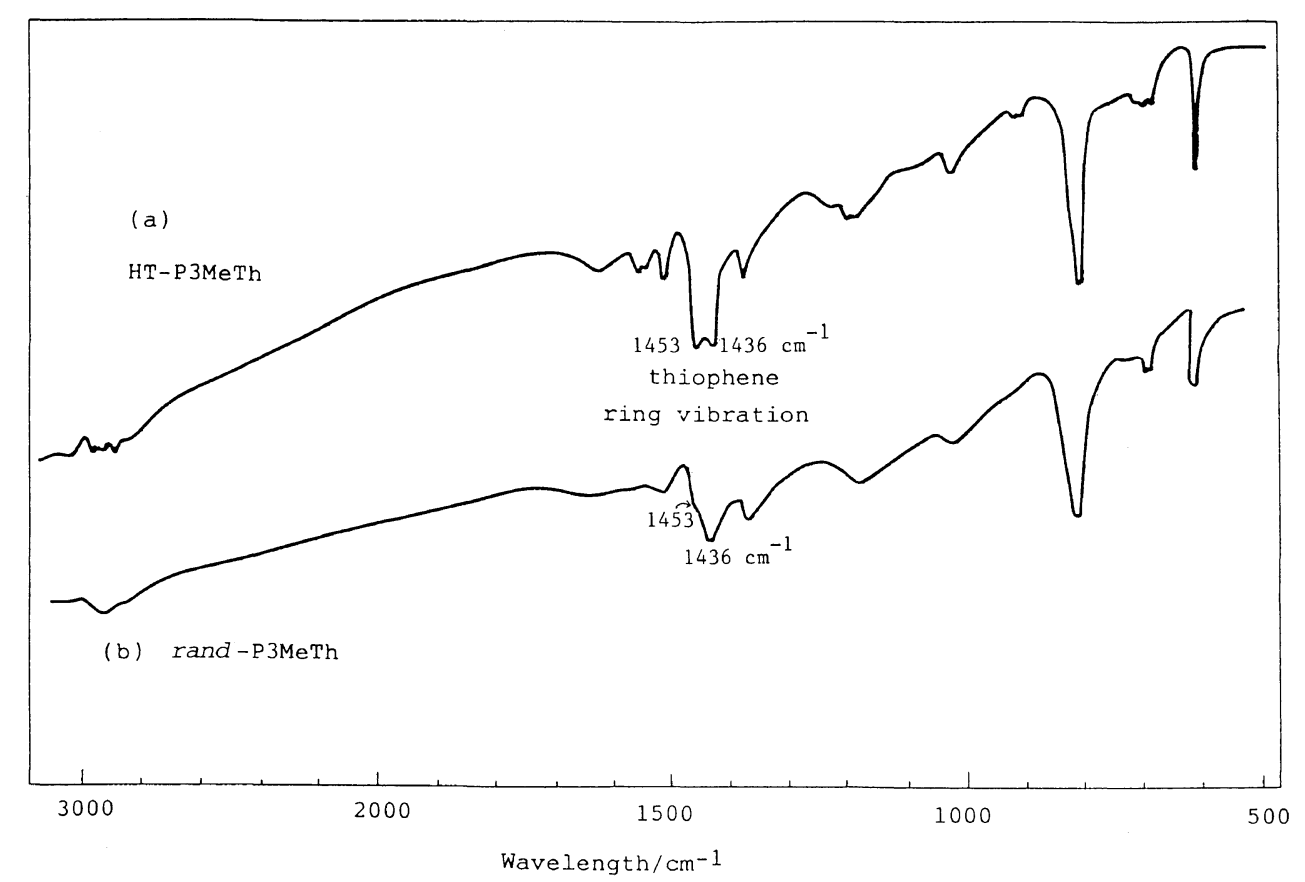

Figure 1. IR spectra of (a) HT-P3MeTh and (b) rand-P3MeTh. ${ }^{3,16}$ 
(b) $\mathrm{HH}-\mathrm{PTz}$
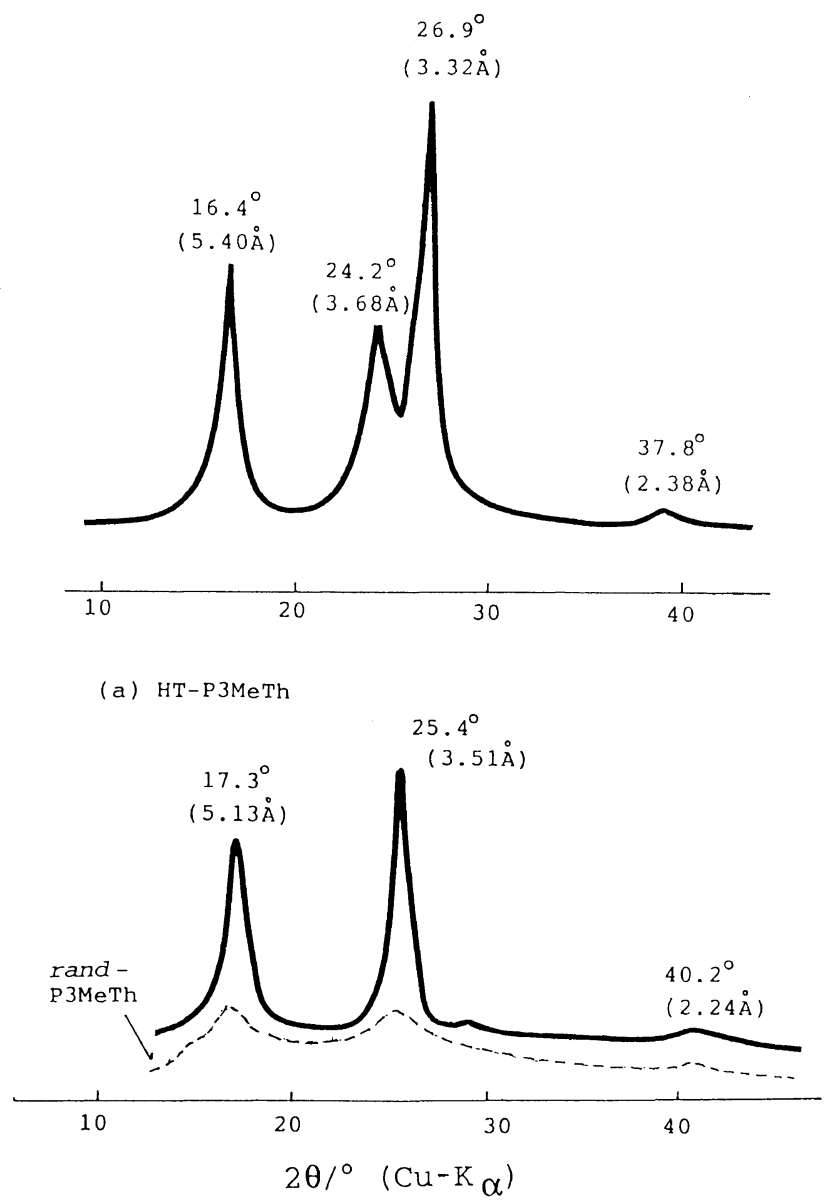

Figure 2. Powder X-ray diffraction patterns of (a) HT-P3MeTh and (b) HH-PTz. The broken line in the part (a) exhibits the powder X-ray diffraction pattern of rand-P3MeTh${ }^{3}$.
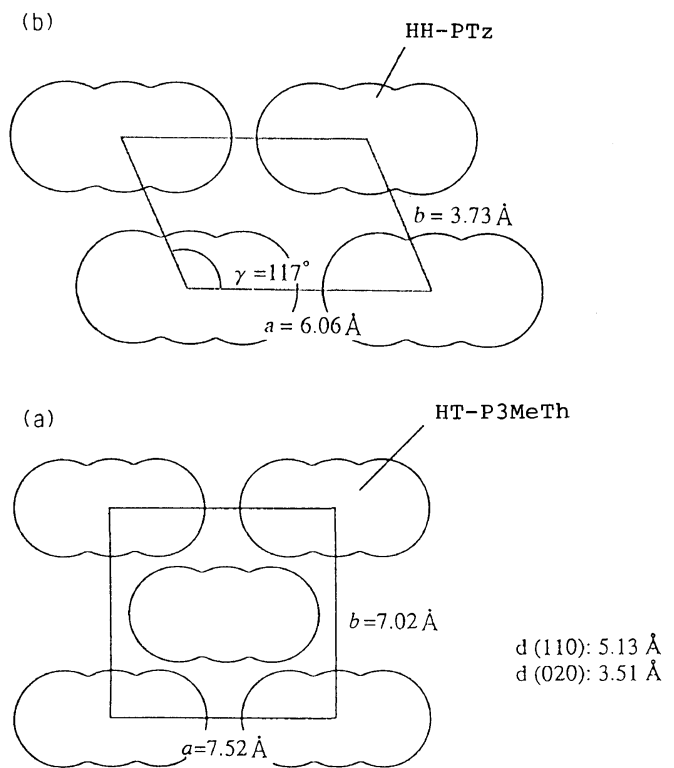

Figure 3. Packing modes of (a) HT-P3MeTh and (b) HH-PTz proposed based on the powder X-ray diffraction data; $c$-axis is the direction of the polymer chain.

that of thiazole $\left(\lambda_{\max }=235 \mathrm{~nm}\right)$. HH-PTz exhibits a photoluminescence peak at $551 \mathrm{~nm}$.

Figure 2 shows powder X-ray diffraction patterns of HT-P3MeTh and HH-PTz, and Figure 3 exhibits the
Table I. Packing modes of HT-P3MeTh, rand-P3MeTh, and $\mathrm{HH}-\mathrm{PTz}$

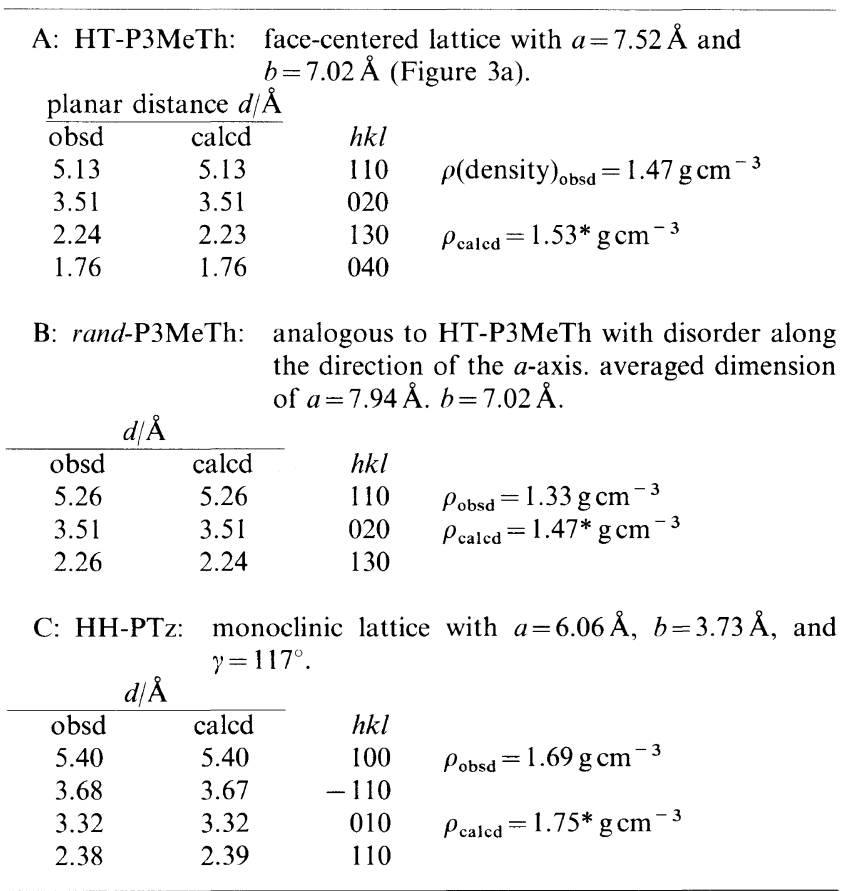

* Calculated based on a assumed heights of $3.85 \AA$ and $3.9 \AA$ for the recurring thiophene and thiazole units, respectively, along the direction of the polymer chain (c-axis).

packing modes of the polymers proposed from the X-ray diffraction data. The sharp X-ray diffraction peaks support the regular structures of the polymers.

Both HT-P3MeTh and HH-PTz give rise to rather sharp diffraction peaks and observed four planar distances $(d)$ for HT-P3MeTh (A in Table I) and HH-PTz ( $\mathrm{C}$ in Table I) agree with the $d$ value calculated based on the packing mode shown in Figure 3. The observed diffraction patterns (including the relative peak strength) also agree with calculated patterns using the linked-atom Rietveld whole-fitting method. ${ }^{7,17}$ This technique can put forward the diffraction pattern with a small number of parameters, and possibly rejects the false structure. Detailed analysis will be reported elsewhere.

The observed densities of the polymers (Table I) are also consistent with the packing modes, although, as usually observed with polymer materials, the observed density is somewhat smaller than the calculated density due to the presence of an amorphous part in the polymer material. For example, the density of HT-P3MeTh is calculated as $\rho=1.53 \mathrm{~g} \mathrm{~cm}^{-3}$ (A in Table I) by assuming a hight of $3.85 \AA^{7}$ for the recurring thiophene unit along the direction of the polymer chain ( $c$-axis), and somewhat lower density of $1.47 \mathrm{~g} \mathrm{~cm}^{-3}$ is observed. Similar relation is observed with HH-PTz (C in Table I).

As for rand-P3MeTh, its X-ray diffraction peaks (the broken line in Figur 2a) are broadened due to its irregular structure without the HT or HH controlling. RandP3MeTh seems to have a packing mode analogous to that of HT-P3MeTh. The face-to-face distance (3.51 $\AA$ ) is identical, however, the 110 diffraction peak at about $2 \theta=17^{\circ}$ is shifted to a longer $d$ space $(5.26 \AA$, B in Table I). These results are reasonably accounted for by existence of various intermolecular distances along the 


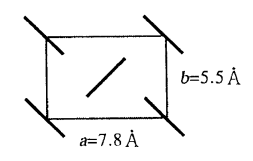

PTh (p2gg type packing) ${ }^{7}$

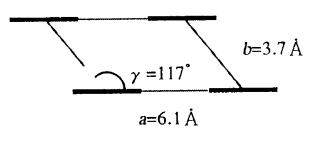

HH-PTz (monoclinic)

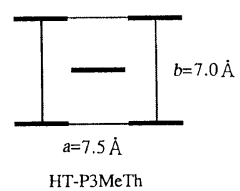

HT-P3MeTh

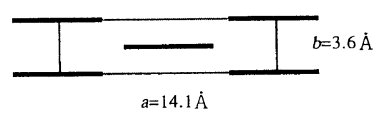

HH-P4MeTz
Chart 1. Packing modes of the polymers. The figures indicate the dimension of the lattice in $\AA$.

$a$-axis due to the irregular lateral shape. A simulated $\mathrm{X}$-ray diffraction pattern obtained by taking account of such disorder agrees with the X-ray diffraction pattern in a range of $2 \theta=5-60^{\circ}$. Due to the presence of the amorphous part in a higher proportion, its density is lowered compared with that of HT-P3MeTh (B in Table I).

By obtaining the packing modes of HT-P3MeTh and HH-PTz, comparison of the packing modes of the above shown (Chart 1) four kinds of polymers becomes possible.

The difference in the packing mode between PTh and HH-PTz as well as that between HT-P3MeTh and HHP4MeTz suggests a stronger tendency of the thiazole ring to form the face-to-face packing. The difference in the packing modes seems to be reflected in their properties (e.g., optical properties), and we are now investigating their properties.

Acknowledgments. We are grateful to Mr. T. Maruyama of our laboratory for experimental support and helpful discussion. This work has been partly supported by a Grant-in-Aid for Science Research from Ministry of Education, Science, Sports and Culture of Japan and CREST (Core Research for Evolutuional Science and Technology).

\section{REFERENCES}

1. T. A. Skotheim, Ed., "Handbook of Conducting Polymers," Vols. I and II, Marcel Dekker, New York, N.Y., 1986.

2. T. Yamamoto, K. Sanechika, and A. Yamamoto, J. Polym. Sci., Polym. Lett. Ed., 18, 9 (1980); Polym. Prepr., Jpn., 28, 966 (1979).

3. T. Yamamoto and K. Sanechika, Chem. Ind. (London), 301 (1982).

4. K. K. Kanazawa, A. F. Diaz, R. H. Geiss, W. G. Gill, J. F Kwak, L. A. Logan, J. F. Robolt, and G. B. Street, J. Chem. Soc., Chem. Commun., 854 (1979).

5. T. Yamamoto, H. Suganuma, T. Maruyama, T. Inoue, Y. Muramatsu, M. Arai, D. Komarudin, N. Ooba, S. Tomaru, S. Sasaki, and K. Kubota, Chem. Mater., 9, 1997, 1217.

6. Y. Kudoh, S. Tsuchiya, T. Kojima, M. Fukuyama, and S. Yoshimura, Synth. Met., 41/43, 1133 (1991).

7. S. Brückner and W. Prozio, Makromol. Chem., 189, 961 (1988).

8. A. M. Echavarren and J. K. Stille, J. Am. Chem. Soc., 109, 5478 (1987).

9. Q. T. Zhang and J. M. Tour, J. Am. Chem. Soc., 119, 5065 (1997).

10. (a) T. Yamamoto, Z.-H. Zhou, T. Kanbara, M. Shimura, K. Kizu, T. Maruyama, Y. Nakamura, T. Fukuda, B.-L. Lee, N. Ooba, S. Tomaru, T. Kurihara, T. Kaino, K. Kubota, and S. Sasaki, J. Am. Chem. Soc., 118, 10389 (1996). (b) T. Kanbara, Y. Miyazaki, and T. Yamamoto, J. Polym. Sci., Part A, Polym. Chem., 33, 999 (1995).

11. R. D. McCullough, P. C. Ewband, and R. S. Loewe, J. Am. Chem. Soc., 119, 633 (1997).

12. K. Diffmer, R. P. Martin, W. Herz, and S. I. Cristal, J. Am. Chem. Soc., 71, 1201 (1994).

13. D. R. Coulson, Inorg. Synth., 13, 1972, 121.

14. M. O. Wolf and M. S. Wrighton, Chem. Mater., 6, 1526 (1994).

15. A. Dondoni, M. Fogagnolo, A. Medici, and E. Negrini, Synthesis, 185 (1989).

16. T. Yamamoto, K. Sanechika, and A. Yamamoto, Bull. Chem. Soc. Jpn., 56, 1497 (1983).

17. S. Sasaki, T. Yamamoto, T. Kanbara, T. Morita, and T. Yamamoto, J. Polym. Sci., 30, 293 (1992). 